\title{
The association of nurse practitioner roles and practice on perceived health of residents living within subsidized housing units
}

\author{
Carole A Orchard ${ }^{1 *}$ and Cornelia Mahler ${ }^{2}$ \\ ${ }^{1}$ Arthur Labatt Family School of Nursing, University of Western Ontario, London, Ontario, Canada \\ ${ }^{2}$ Nursing Science Department, Institute of Health Sciences, Medical School Eberhard Karls University Tübingen, Germany
}

\begin{abstract}
Design: This study focused on a cross sectional evaluation of a project where nurse practitioner led primary health care clinics were provided to residents living within subsidized housing units in a southwestern Ontario, Canadian city over a 10-month period of time.

Question: The study focusses on assessing how gaining access to health care provided by the NPs impact their capacity and completeness to deal with their own health.

Sample: A total of 110 residents who used the clinics services and 70 residents who chose to use health services provided by other health providers outside of the housing units participated in individual structured interviews.

Methods: The survey instrument underwent psychometric analysis and the results were then used to analyse the data from the residents. Comparisons between users and non-users data of the NP provided care on their: capacity and competence from their satisfaction with NP care led on their perceived ability to manage their own health.

Implications: The role of Nurse Practitioners when enacted through a strength based relational model of care can demonstrate enhance health outcomes among people who often feel marginalized from the health care systems.

Conclusion: The findings demonstrated a statistically significant relationship with residents' perceived Health with NP primary care was found, as compared to those residents who did not use these NP services. However, there are a number of limitations in this study that require the findings to be considered with caution.
\end{abstract}

\section{Introduction}

The challenge of providing quality primary care services for populations in countries with socialized health delivery programs has resulted in a variety of service models - family health teams, community health centred, nurse practitioner-led clinics, etc. While these models are available issues continue about how these services are provided within primary health [1]. Interestingly access to care has been identified as one of seven quality attributes of Davis et al. [2]. Other attributes include: patient engagement, information systems, care coordination, comprehensive team care, patient-centred surveys, and publicly available information [2]. Access to care appears to have two dimensions: having access, meaning availability of health care if needed, and gaining access, meaning obtaining health care that is responsive to individual clients' needs [3].

How public assess their access to care seems to be influenced by its: acceptability, affordability, and accommodation. Acceptability focuses on how satisfactory services provided are to individuals. Affordability relates to expenditures needed for individuals to access their health services. In countries with socialized health services such as Canada, affordability is considered in context of time and travel costs in order to obtain care and availability of child care for mothers of young children seeking their own health care. Thus, affordability is not just strictly financial, but also associated with costs in terms of time and energy. Accommodation relates to how well services are adapted to perceived patient needs [2]. Hence, accessibility can be perceived differently from perspectives of system providers, health services providers, and recipients of these services. In this paper, we will focus specifically on clients (In the remainder of this paper we will refer to clients in the housing units as residents) perceptions of acceptability, accommodation and affordability of their primary healthcare provided by nurse practitioners within clinics situated in subsidized housing units and not on objective measures of service availability.

\section{Literature review}

At the time of this study, there was a discrepancy in health care access between 'orphan' patients (i.e. those without a regular family physician) in a Canadian Southwestern Ontario city and the general population. Ten percent of the general population experienced lack

${ }^{\star}$ Correspondence to: Carole A Orchard, Arthur Labatt Family School of Nursing, University of Western Ontario, London, Ontario, Canada, E-mail: corchard@uwo.ca

Key words: nurse practitioner care, strength-based model of care, instrument measurement, perceived ability to manage health, capacity, satisfaction

Received: November 10, 2018; Accepted: November 25, 2018; Published: November 29, 2018 
of regular family physicians while those living in this city's subsidized housing units reported up to 50\% [4]. For this latter group, their only means of accessing health care was provided by either walk-in clinics or hospital emergency departments; neither of which are designed to provide ongoing care. Thus, access to needed care was less available to those with lower socioeconomic status than others in the same city. Mikkonwn and Raphael [5] reported that those with poorer health outcomes, tend to have lower access to needed care. Even when those who are able to access primary health care, they often experience a social distance between themselves and their providers who judge them for choices they make without appreciating their actual situations [6]. Once access is obtained, it depends on how those coming to seek help gaining access through care acceptability, accommodation and affordability.

\section{Acceptability}

Acceptability of care access relates to individuals' rate their satisfaction with health services. Thus, acceptability may have different meanings to a single mother living in subsidized housing in an urban setting who has to take three buses to reach a primary care provider, as compared to a similar group in a rural one who has to travel to another town to received care. However, overlaps in perceptions between the two groups, may occur with possible magnitude differences. Wong and Regan [7] conducted a qualitative study of rural patients and their access to primary care and found three themes related to access: making trade-offs, continuity of care, and efficiency. Participants reported on high costs of travel for follow-up care, time involved in travelling to major centres for care, and waiting times endured [7]. Interestingly, in urban settings, getting to health providers for care also caused travel issues. Women found lack of child care frequently meant taking their young children on several buses to get to their health providers. They often arrived late because of bus schedules, were chastised for their tardiness and made to wait long periods to see their providers. These waits caused more stress in finding the means to keep their children quiet in waiting rooms. As a result, some women in this study reported choosing not to seek their own health care and only sought help for their children when they were ill. Thus, accommodation to clients' needs is also an important feature of gaining access to health care.

\section{Accommodation}

Accommodation relates to how health services are adapted to perceived needs of those seeking care. In the Wong and Regan study, rural women also discussed the impact on their health, resulting from health provider turnovers in rural areas. Urban women living in subsidized housing also experienced a lack of consistent access to specific health providers. In both cases, turnovers, or changes in providers resulted in disruption of their health provider developed relationships. Such disruptions can have negative impacts on their health [7]. Results from a survey of chronically ill clients from eight industrialized countries revealed that when a continuous relationship existed with their health providers, it enabled timely and more likely coordinated delivery of care across providers and services reflective of their health needs. Kuzel et al. [8] interviewed 40 patients about their primary health care experiences. Many of the respondents commented that relationship breakdowns resulted from inadequate time that resulted in disrespectful and insensitive interpersonal communication with providers. The outcome was feelings of belittlement or anger and frustration with providers. Thus, a key issue in acceptability, and accommodation in primary care relates to relationship clients have with their health providers.

\section{Affordability}

Affordability relates to individual client expenditures in time, in energy, and in costs to gain health services access. People's personal expenditures in gaining access to health services may affect their sense of competence and capacity to improve their health. Taking action in improving their health may be based on trusting the quality of advice, encouragement, and information they have with their health providers. Bandura [9] suggests that individuals can find themselves in three different types of relational situations- imposed, selected, or constructed. Each situation can have a direct impact on an individuals' capacity to make decisions. In health care, clients often find themselves in situations dictated by their socioeconomic and educational characteristics. Thus, physician may have reservations about clients becoming more involved in their care related to their personal beliefs about peoples' limitations in cognitive capacity, ability to process information, and objectivity in shaping their own care [10]. Interestingly in a literature synthesis, Auerbach [11] reported on lack of evidence to support these physician assumptions about patients. However, in the Street Jr. and Epstein [10] study physician were poor judges about patient beliefs unless patients were encouraged to participate in their interactions. Alternatively, clients may consciously readjust their situations by choosing when and if they will seek health services, or by re-constructing their lives to meet their desired sense of capacity over how they will use services offered [4]. The quality of the information about their health received by clients made healthcare services acceptable Auerbach [11] and when progress expectations were adapted to their personal capacity to manage their own health [12].

\section{Satisfaction with care}

In a review of several studies on satisfaction with care among adult clients receiving primary health care have reported mixed results. These studies were carried out in the US [13-15], and U.K [16] and focused on clinical outcomes, prescribing practices, and consultations by nurse practitioners or primary care physicians. None of the above studies reported differences in patient outcomes. Horrocks et al. [17], as well as Venning et al. [16] reported greater satisfaction with nurse practitioner care associated with longer duration consultations and more investigations (e.g. tests, $\mathrm{x}$-rays etc.). In a systematic review of studies from 1970 until 2006 by Naidu [18] identified client satisfaction was predicted by caring, empathy, reliability and responsiveness. Horrocks et al. [17] in a systematic review of equivalency of care between nurse practitioners and doctors found that NPs provided more complete records of care, scored higher than physicians on communications, and more advice on self-care management. In contrast, Litaker et al. [13] found that when nurse practitioners and physicians worked in teams, higher levels of satisfaction with care were found as compared with physician only care. Agosta [19] is one of few studies located about client satisfaction with nurse practitioner's primary healthcare practice in the US found overall satisfaction with NP visit, NP respected me and NP is caring as the highest ratings. Lenz et al. [14] suggest that greater satisfaction with nurse practitioner care may be due to their professional socialization processes. No studies were located that focused on broader understanding of NP practice supporting patients' capacity over their own care, their confidence to manage their health care, or the above factors impact on patients' level of satisfaction with their NP provided care.

Lafond, Brown and Macintyre [20] suggest that individual capacity relates to an inter-connection between a person's ability to engage in health services and improvement of his/her perceived 
health. Therefore, an interconnection needs to exist through relational partnerships between clients and their health practitioners [21]. Further, when attention is paid to valuing and respecting people's capacity to engage in this partnership reflecting trust and caring, the result is likely to be a sense of purpose and capacity, which in turn can potentially enhance their health [22]. Hence, a key to residents' in this study's capacity building is providing mutual relationships with their nurse practitioners "characterized by balance in control between [both parties]..., ... [causing] decision making... [to] more likely... be participatory" [10]. As a result, this capacity may be influenced by residents' perceived competence to enact measures to enhance their health.

\section{Project}

In 2009, the Interprofessional Care Learning Labs Project (IPCLLP) was funded by the HealthForceOntario grant program to implement a nurse practitioner-led clinic in two subsidized housing units and to continue the operation of a third clinic site housed within a crisis centre for children and families in a southwestern city in Ontario. The IPCLLP was designed to test implementation of the Western Model for Family Health and Social Care (Figure 1), specifically residents' perceived satisfaction with their care, capacity with their own care, and competence to manage their own health. This project provided a unique collaborative approach among the city's housing corporation, the city's community services staff, two non-government organizations funded through their own boards of directors, faculty from the local university, and with the sites residents (Resident is the label those living within the subsidized housing units requested).

The above model incorporated the work developed around the Developmental Model of Health and Nursing created by Allen and Warner [23] and implemented locally by Ford-Gilboe [24]. This model was expanded on to incorporate an interprofessional client-centred collaborative care model defined as "a partnership between a team of health providers and a patient, where the person retains control over his/her care and is provided access to the knowledge and skills of team members to arrive at a realistic shared plan of care and access to the resources to achieve the plan" [4]. Thus, the IPCLLP integrated a broad model of interprofessional care and education in providing residentcentred collaborative care.

The purpose of this study was to determine the association between residents' of two subsidized housing units use of NP delivered health care and their ability to manage their own health, as compared to those residents who did not use these NP care services? Specifically, to examine the relationship between nurse practitioner provided care to the residents and how their perceived accessibility and affordability measured by satisfaction with care provided and accommodation related to how their care affected their capacity, competence and ability to manage their health as a result of using the nurse practitioner services in the subsidized housing unit clinics.

\section{Conceptual framework}

Residents who live within marginalized communities, such as subsidized housing units, can experience barriers in gaining access to their health care. At the same time those living within these communities, may experience physical and mental health challenges as a result of the situations in which they find themselves. These challenges may in turn limit their ability to access health services that limit their continuity of care to manage their own health. The relationships clients experience with their health providers can increase their capacity for and perceived competence to address their health challenges leading to their ability to manage their health and satisfaction with the care provided (Figure 2).

\section{Study design}

This study employed a cross-sectional design using a structured questionnaire with a convenience sample of residents who lived in two subsidized housing units in a Canadian southwestern Ontario city.

\section{Ethical aspects}

This study received ethics approval from the University of Western Ontario's Research Ethics Board. Written informed consent was obtained from all participants. Participants received \$20 (CDN) to compensate them for their time participating in the study.

\section{Participants/Recruitment}

A convenience sample of 180 residents (110 users of the clinics and 70 non-users of the clinics) were recruited from the two subsidized housing units in the same community. Participants were recruited through flyers delivered to all housing unit townhouses and through personal approaches to residents by other housing unit residents. Comparison between the groups was conducted in order to examine similarities or differences that might be related to their chosen health care location options.

An independent samples $t$ test was carried out to compare demographic characteristics of the two groups. The groups were similar in their marital status $(M=2.73, \mathrm{SD}=1.047, t=0.942, p=0.32$ twotailed), employment $(M=0.190, \mathrm{SD}=0.393, t=0.925, p=0.36$ twotailed) and total income $(\mathrm{M}=2.64, \mathrm{SD}=1.691, t=0.764, p=0.45$ twotailed). However, they varied in gender, age and education level. The magnitude in the differences in means was: gender (mean difference $=1.314$ ), education levels (mean difference $=1.208$ ) and age (mean difference $=4.524)$ with a $95 \% \mathrm{CI}(0.609$ to 7.530$)$. In the user group, three quarters of respondents were female, while in the non-user group females were less than one-half $(t=1.495(d f 23), p=0.15)$ (Table 1).

Table 1. Participant demographic characteristics

\begin{tabular}{|l|c|c|}
\hline $\begin{array}{l}\text { Demographic } \\
\text { characteristics } \\
\text { Sample size n= 180 }\end{array}$ & $\begin{array}{c}\text { User of the clinics } \\
\text { (n= 110) }\end{array}$ & $\begin{array}{c}\text { Non-user of the clinics } \\
(\mathbf{n}=\mathbf{7 0})\end{array}$ \\
\hline Age(n/SD/range) & $33.7(9.4)[18-67]$ & $29.6(9.9)[18-60]$ \\
\hline Gender & $25(22.7)$ & $39(55.7)$ \\
\hline Male & $85(77.3)$ & $31(44.3)$ \\
\hline Female & & $34(48.6)$ \\
\hline Marital status & $43(39.1)$ & $25(35.7)$ \\
\hline Single/Never married & $48(43.7)$ & $10(14.3)$ \\
\hline Married/Common Law & $17(15.4)$ & $1(01.4)$ \\
\hline Divorced/Separated & $2(01.8)$ & $6(08.5)$ \\
\hline Widowed & $7(06.3)$ & $68(78.6)$ \\
\hline Highest education attainment & $62(68.3)$ & $9(12.9)$ \\
\hline Elementary Education & $28(25.4)$ & \\
\hline High School & & $68(97.1)$ \\
\hline College/University & $100(90.9)$ & - \\
\hline Preferred language & $1(0.9)$ & $24(34.3)$ \\
\hline English speaking & $9(8.2)$ & $56(80.0)$ \\
\hline French speaking & $34(30.9)$ & \\
\hline Other & $25(23.6)$ & \\
\hline Visible minority N (\%) & $84(76.4)$ & \\
\hline Employment & & \\
\hline Employed & & \\
\hline Not employed & & \\
\hline
\end{tabular}




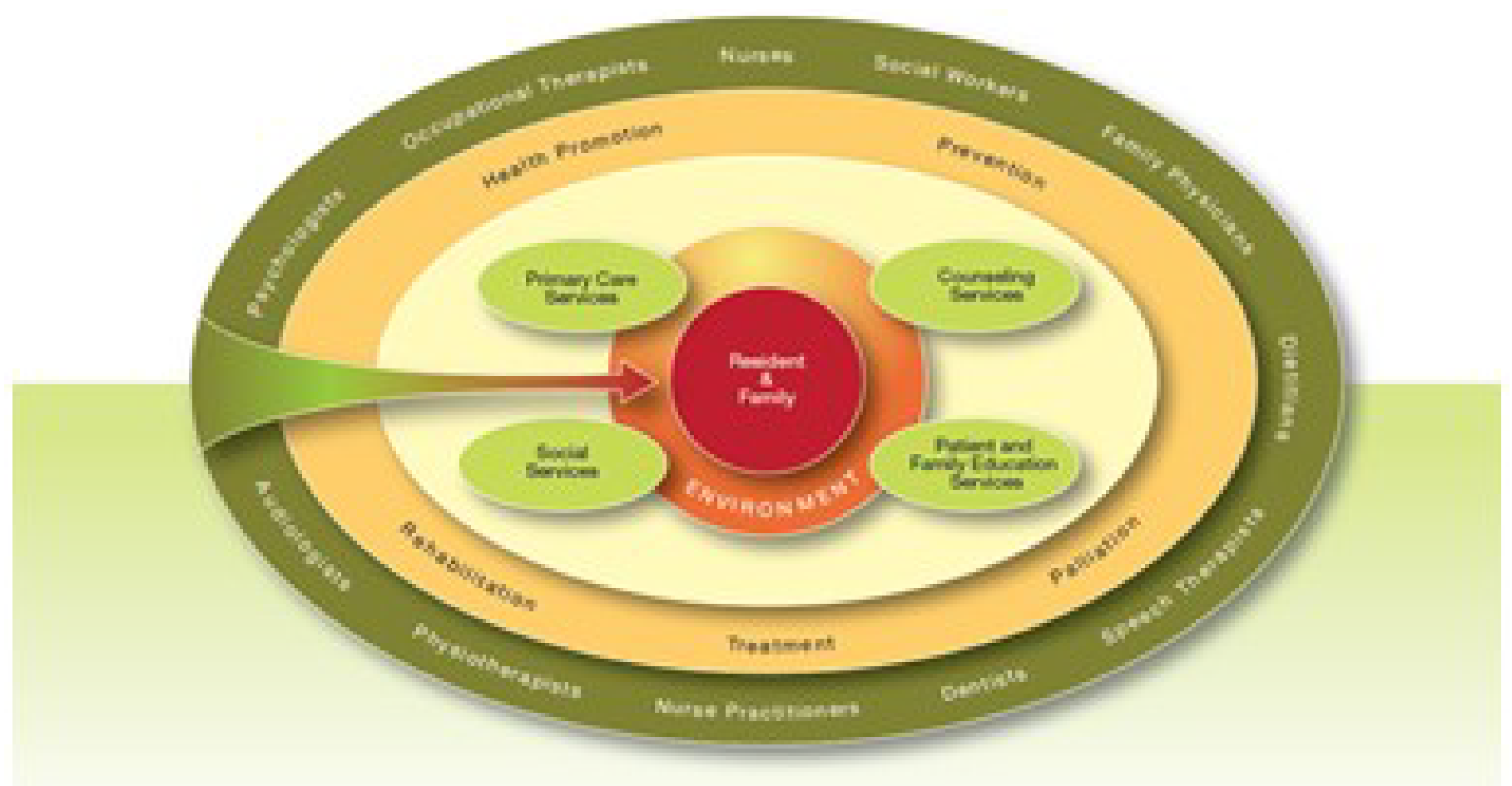

Figure 1. Centre for family health clinic model

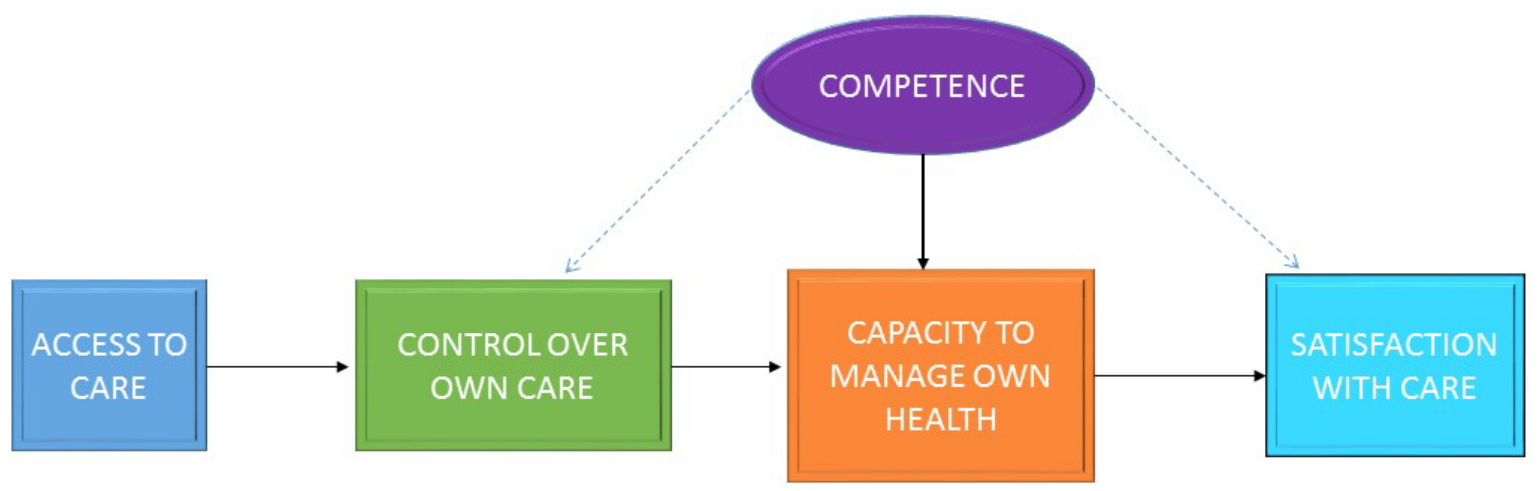

Figure 2. Study conceptual relationships for testing

\section{Methods}

\section{Data collection}

The structured interview instrument in addition to above demographic questions contained 37 items comprising four constructs: (a) satisfaction with nurse practitioner care (13 items); (b) personal capacity (10 items) (c) competence (7 items); (d) perceived health (7 items). All items were rated using a 5-point scale. Questions were designed to gather similar types of information from both users and nonusers with items varying in slightly different that did not change the substantive intent of the items in either instrument versions. For each of the concepts, participants were asked to consider health services they had received in the past 10 months (duration of the project) from clinic nurse practitioners (NPs) (user group) or from their usual care provider (non-user group).

The focus was on the residents (participants) provided information about health services they accessed for themselves - not their family members. They had a choice of completing the questionnaire on their own or being interviewed by a graduate student who was not part of the project. Most of the respondents selected to be interviewed in either their own homes or in a private office in the clinic sites. Interviews were approximately one hour, carried out in a private office in one of the two clinic sites. Information on the number of residents approached for interviews and who refused is not available.

\section{Testing of instrument for study}

The questionnaire used in the structured interview is an expanded version created by Ford-Gilboe to measure the developmental health nursing model impact for such communities. However, it had not been assessed for its validity and reliability. Hence, following collection of data, psychometric testing was required prior to analysis of data. Concepts in the instrument with similar rating scales were: Capacity (11 items), Competence (14 items), Satisfaction 25 items), and Health/Quality of Life (11 items). Separate items for Access were not included due to divergence from concept ratings in the measure. Since some items in the other retained concepts related to acceptability, 
accommodation, and affordability in gaining access to health service it was felt gaining access was still being assessed. Data analyses were performed using SPSS software package 25 [25].

Initially the total resident respondents (users and nonusers of the services) demographic data were analysed followed by all items in the above concepts to assess for normality, multicollinearity, and outliers. Two apparent outliers were found but determined to not influence the model [26]. A descriptive analysis was then carried out for the total respondent datasets (Table 2) followed by both an exploratory factor analysis and a path analysis.

\section{Exploratory factor analysis}

$\mathrm{KMO}$ and Bartlett's Test indicated all items were within the norms to carry out an Exploratory Factor Analysis (EFA). The results of these EFAs are listed below with the final number of items retained (Table 2). Satisfaction was the only concept that had more than a single dimension. Its three sub-concepts were: Patient Valuing (6 items), Individualized Care (3 items) and Information Options (4 items) (Table 3 ).

The resultant instrument the Nurse Practitioner Support on Client Management of Health (NPS-CMH) was comprised of 34 items that was then used to determine relationships between the concepts (Table 4).

\section{Path analysis}

Hierarchical multiple regression was used to assess the ability of one control measure (Health) to predict levels of Satisfaction, after controlling for the influence of Capacity and Competence [27]. Preliminary analyses were conducted to ensure no violation of the assumptions of normality, linearity, multicollinearity and homoscedasticity. Capacity and Competence were entered at Step 1, explaining $32.7 \%$ of the variance in Satisfaction. After entry of Health at Step 2 the model total variance was $45.2 \%,(F 3,36.82, p<0.001)$. The two control measures explained an additional $37.8 \%$ of the variance in Satisfaction, after controlling for Capacity and Competence, ( $R$ squared change $=0.42, F$ change $=1,26.23, p<0.001)$. In the final model, only Capacity and Satisfaction were statistically significant, with Satisfaction recording a higher $\beta$ value $(\beta=0.430, p<0.001)$ than the Capacity scale $(\beta=0.359, p<0.001)$. Therefore, the capacity residents have in their satisfaction with their care seems to result in their ability to manage their health. Competence in their ability however does not seem to have any direct effect upon either their satisfaction with care or ability to manage their health (Figure 3).
While the results do not demonstrate a relationship between competence and satisfaction and ability to manage their health due to the sample size $(\mathrm{n}=180)$ it was decided to retain competence in the overall analysis until further testing of the instrument can be carried out.

\section{Data analysis}

To address the overall research question "What is the relationship on residents' of two subsidized housing units, ability to manage their own health among those with NP provided primary care, as compared to those residents who did not use these NP care services?" Descriptive and inferential statistics appropriate to the level of data were computed for all study variables. Descriptively means, standard deviations comparisons between groups (users, non-users) were assessed finally independent sample t-tests were carried out to assess for significant differences between the two groups on each of the constructs. The level of significance for all analyses was $p<0.05$.

\section{Results}

\section{Descriptive analysis}

Initially the means, and standard deviations were analysed together and then compared between users and non-users of the NP care for total satisfaction $(M=40.99, S D=9.234)$ capacity $(M=58.47, S D=$ $9.198)$, competence $(M=7.63, S D=2.550)$ and health $(M=25.09, S D$ $=6.462$ ). Comparison between the users and nonusers are shown in table 5 .

Users (U) consistently reported higher means for satisfaction ( $M$ $=43.80, S D=7.25)$ with the care provided as compared with nonusers (NU) $(M=30.80, \mathrm{SD}=8.54)$. Similar patterns were observed in capacity (U: $M=52.98, \mathrm{SD}=6.84 ; \mathrm{NU}: M=43.20, \mathrm{SD}=7.53$ ); confidence (U: $M$ $=8.41, \mathrm{SD}=2.00, \mathrm{NU}: M=6.50, \mathrm{SD}=2.80)$; and finally their perceived health (U: $M=27.88, \mathrm{SD}=4.77, \mathrm{NU}: M=18.83, \mathrm{SD}=6.60$ (Table 5).

An independent samples $t$-test was carried out to compare satisfaction, capacity, confidence and health scores between users and non-users of the NP led clinic services. There was a significant difference in scores for all four of the concepts between users and nonusers -for satisfaction ( $t$ (139 $=8.333, p<0.0001$ two-tailed); for capacity $(t(138)=6.773, p<0.0001$ two-tailed); for competence $(t$ $(138)=3.491, \mathrm{p}<0.0001$ two-tailed $)$; and for health $(t(138=7.052, p$ $<0.0001$ two-tailed). The magnitude of mean differences varied from the highest in satisfaction (mean difference $=13.015$ 95\% CI: 9.926 to 16.103); followed by capacity (mean difference $=9.78,95 \%$ CI: 6.926 .47

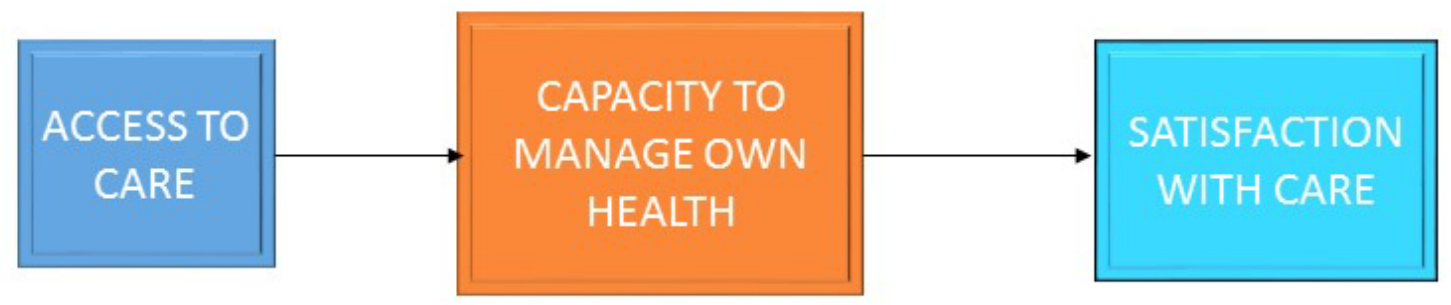

Figure 3. Predictive model of the relationship between access to NP provided care residents' satisfaction with the care

Table 2. Descriptive analysis of concepts means and standard deviations by concept

\begin{tabular}{|l|c|c|c|}
\hline Concepts & N & M & \\
\hline Satisfaction (13 items) & 138 & 40.99 \\
\hline Capacity (12 items) & 138 & 58.53 \\
\hline Competence (2 items) & 138 & 7.993 \\
\hline Health (7 items) & 138 & 2.326 \\
\hline
\end{tabular}


Table 3. Figure concepts with EFA results and correlations

\begin{tabular}{|c|c|c|c|c|c|c|}
\hline Concept & $\begin{array}{l}\text { Factors with eigen } \\
\text { values above } 1.00\end{array}$ & $\begin{array}{l}\text { Cumulative \% of } \\
\text { Variance }\end{array}$ & Dimensions & $\begin{array}{l}\text { No. of Items } \\
\text { Retained }\end{array}$ & No. of Items Excluded & Pearson Correlation \\
\hline Capacity & 1 & 42.50 & Unidimensional & 10 & 1 & $\begin{array}{l}0.591 \\
(p<0.001)\end{array}$ \\
\hline Competence & 1 & 9.11 & Unidimensional & 7 & 7 & $\begin{array}{l}0.253 \\
(p<0.001)\end{array}$ \\
\hline Satisfaction & 3 & & $\begin{array}{l}\text { Patient Valuing } \\
\text { Individualized Care } \\
\text { Information Options }\end{array}$ & $\begin{array}{l}6 \\
3 \\
4\end{array}$ & $\begin{array}{l}7 \\
4 \\
0\end{array}$ & $\begin{array}{l}0.616 \\
(p<0.001)\end{array}$ \\
\hline Health & 2 & 75.92 & Unidimensional & 7 & 7 & \\
\hline
\end{tabular}

Table 4. Items by scales and subscales for Nurse Practitioner Support on Client Management of Health (NPS-CMH)

\begin{tabular}{|c|c|c|}
\hline Concept & Item & Factor Load \\
\hline \multirow{13}{*}{ Capacity } & \multicolumn{2}{|l|}{ As a result of the care I received from my usual health care provider(s)... } \\
\hline & I feel less alone & 0.509 \\
\hline & I feel more supported & 0.630 \\
\hline & I have a better understanding of my situation & 0.644 \\
\hline & I am more aware of what I can do to improve my situation & 0.677 \\
\hline & I am more aware of my strengths & 0.681 \\
\hline & I have new ways of looking at my situation & 0.641 \\
\hline & I feel better about my relationship with others & 0.684 \\
\hline & I am more connected to family/friends & 0.561 \\
\hline & I am more connected to my community & 0.455 \\
\hline & I am better able to seek help from other community services & 0.546 \\
\hline & I am more able to meet the goals I set & 0.599 \\
\hline & I am more motivated to make changes that are important to me and my family. & 0.619 \\
\hline \multirow{3}{*}{ Competence } & \multicolumn{2}{|l|}{ As a result of the care I received from my usual health care provider(s) } \\
\hline & I am more able to keep my family healthy & 0.918 \\
\hline & I am able to make better choices about things that affect the health of my family. & 0.881 \\
\hline Satisfaction & My usual health provider... & \\
\hline \multirow{5}{*}{ Value Person } & Respected me as a person & 0.687 \\
\hline & Understood what is important to me & 0.542 \\
\hline & $\begin{array}{l}\text { Took the time to understand my concerns } \\
\text { Gave me useful information }\end{array}$ & 0.744 \\
\hline & Was flexible in meeting my needs & 0.749 \\
\hline & Encouraged me to come and see him/her or call when I need to & 0.550 \\
\hline \multirow{3}{*}{ Individualized Care } & Remembered my situation without me having to describe it over and over & 0.505 \\
\hline & Supported me in discussing issues or concerns I have about my mental/emotional wellbeing & 0.738 \\
\hline & Encouraged me when I was not motivated & 0.674 \\
\hline \multirow{3}{*}{ Providing Options } & $\begin{array}{l}\text { Told me about resources or services that might be helpful to me } \\
\text { Suggested treatments, interventions and/or services that fit with your life }\end{array}$ & 0.540 \\
\hline & Helped me clarify what I need from other health providers & 0.828 \\
\hline & Explained treatments, interventions, and/or services suggested by other health care providers & 0.702 \\
\hline \multirow{7}{*}{ HEALTH } & I feel better about myself & 0.691 \\
\hline & I feel more hopeful & 0.682 \\
\hline & I feel less distressed & 0.600 \\
\hline & I am better able to carry out my daily activities & 0.648 \\
\hline & My physical health interferes less with my family and social activities & 0.604 \\
\hline & My mental/emotional health interferes less with my family and social activities & 0.559 \\
\hline & My overall quality of life has improved & 0.712 \\
\hline
\end{tabular}

Table 5. Means and Standard Deviations between Users and Nonusers on each construct in the instrument

\begin{tabular}{|c|c|c|c|c|c|c|c|}
\hline \multirow[b]{2}{*}{ Concepts } & \multicolumn{3}{|c|}{ Users } & \multicolumn{4}{|c|}{ Non-users } \\
\hline & $n$ & $M$ & $S D$ & $n$ & $M$ & $S D$ & $p$ \\
\hline Satisfaction (13 items) & 109 & 43.799 & 7.249 & 30 & 30.800 & 8.544 & $<0.001$ \\
\hline Valuing Person (6 items) & 109 & 23.229 & 1.687 & 30 & 17.900 & 4.751 & $<0.001$ \\
\hline Individualized Care (3 items) & 109 & 8.156 & 4.040 & 30 & 5.800 & 2.930 & 0.003 \\
\hline Providing Options (4 items) & 109 & 12.304 & 4.518 & 30 & 7.100 & 3.854 & $<0.001$ \\
\hline Capacity (12 items) & 108 & 52.982 & 6.844 & 30 & 43.200 & 7.534 & $<0.001$ \\
\hline Competence ( 2 items) & 108 & 8.407 & 2.000 & 30 & 6.500 & 2.801 & $<0.001$ \\
\hline Health (7 items) & 108 & 27.880 & 4.773 & 30 & 18.833 & 6.561 & $<0.001$ \\
\hline
\end{tabular}


to 12.637 ); then health (mean difference $=9.781,95 \%$ CI: 6.922 to 11.171 ) and Competence had the lowest variance (mean difference $=$ 1.907, 95\% CI: 0.801 to 3.014). The effect sizes in Capacity and Health were small, while in Satisfaction, and Confidence were large (eta squared was from 0.2 to 0.6 ).

The higher mean difference between $\mathrm{U}$ and $\mathrm{NU}$ within the concept of Capacity were related to "having a better understanding of your situation" (mean difference 1.499), and within Satisfaction "suggested treatments, interventions, and/or services that fit with your life" (mean difference $=1.576)$, "flexible in meeting needs" (mean difference $=1.35)$, "helped clarify what you need from other health care providers" (mean difference $=1.34$ ) and "told about resources or services that might be helpful" (mean difference 1.32). Both U and NU rated "respect you as a person" (nonusers $M=3.43, S D=0.897$; users $M=3.936, S D=0.311$ )) as their highest. The users also valued that NPs "took time to answer your questions" (M 3.882, SD 0.400), "gave me useful information" $(M=$ $3.864, S D=0.497)$, "were flexible in meeting your needs" $(M=3.846, S D$ $=0.528)$, and "encouraged you to come see her or call when you need to" $(M=3.846, S D=0.638)$.), all of these items were within the Satisfaction concept. While the NU also rated "you have new ways of looking at your situation" $(M=3.422, S D=0.897)$, "you are more aware of our strengths" $(M=3.300, S D=0.987)$ "you are better able to seek help from other community services" $(M=3.467, S D=0.819)$, "you can cope with your situation better" $(M=3.412, S D=0.966)$ which were items within the Capacity concept with only "respected you as a person" (noted above) and "encouraged you to come see her/him or call when you need to" $(M=3.167, S D=1.053)$ within the Satisfaction concept.

Thus, there were differences in all the concept means between $U$ and NU of the NP led clinic services. A statistically significant relationship with residents' perceived Health with nurse practitioner primary care was found, as compared to those residents who did not use these NP primary health care services. An interesting finding was that nonusers seem to use their own Capacity to manage their own health that may have not been influenced by their health providers with the exception of the two items noted above in the non-users satisfaction concept. However, these findings must be considered with caution as both users and nonusers were not representative, and the sample size was small.

\section{Discussion}

A relationship was found between residents' perceived health, capacity and satisfaction in managing their own health, favouring those who had NP services. The findings of statistically significant differences in resident satisfaction supports Horrocks et al. [17] and Venning et al [16] findings of patient's high satisfaction with NP provided care. The clinic users consistently reported higher means compared to nonusers for all four measured constructs. Hence, it appears that clinic NP support may result in greater satisfaction than usual health providers' support for non-users. While this study focused on how residents gaining access to NP provided services were able to manage their own health as an outcome, other factors not studied may also have influenced these findings.

It appears that relationships may have evolved with NPs taking time to understand the residents' needs and responding appropriately to them. These aspects appear to be valued by residents, which fits with Smith et al. assertion that social relationships reflecting trust and caring create a sense of both purpose and being valued as a person [28]. Thus, relational aspects between residents and the NPs may have provided acceptability, accommodation and affordability in their care by residents using their services leading perhaps to better perceived health.
At the same time the nonusers also reported capacity in managing their own health as well, although at lower levels that those of the users.

These relationships between clinic users and NPs may have also resulted in differences in satisfaction scores between users and nonusers. The findings of ability to manage health as an outcome of NP care in the clinics may have led to an individual's capacity to use benefits from the NP services in gaining a perceived ability to manage their own health. This finding is supported by Lafond et al. [20] who suggest when individuals gain ability to engage in accessible health services, this can result in perceived improvement in their health.

It seems that both the location of a clinic within a community, along with the relationships established between the NPs and the residents, may have contributed to the findings. The location of clinic sites situated within their community (subsidized housing unit) and close to their homes, addressed some affordability issues in expending time to travel and to seek child care issues. These issues often impact on urban living people who are expected to fit into scheduled appointments in traditionally located health provider clinics that are often at a distance from their homes. It also appears that the relational care philosophy provided, using a strengths-based approach, may also have addressed accommodation issues for these residents who often report stigma towards them in other studies. In the case of this study it appears that the residents found the care they received was adapted to their perceived needs. Thus, the social environment supporting accommodation created by NP/resident relationships may well have enhanced these findings.

These relationships seemed to provide partnerships between residents and NPs in which residents could select care they were ready to accept, or the NPs could construct and guide their care leading to their increased capacity leading to a perceived ability to manage their health as Bandura [9] advocates. NPs openness to listen to residents and help them shape what issues they needed to discuss about their health may also influence higher satisfaction rates for NP care than for other health providers of non-clinic users. The resulting collaborative relationships between NPs and residents likely created a sense of caring at a level of acceptability to the residents as compared to barriers they had experienced previously. These enhanced social relationships between NPs and residents may have improved residents perceived quality of their care as suggested by Campbell et al. [29] and Freudenberg et al. [30]. It is possible that these relationships also fostered partnerships between the NP and residents that were seen as suggested by Street and Epstein [10] to provide mutuality across the parties and may also have mitigated perception among residents of health providers as being disrespectful and insensitive from Kuzel et al.'s [8] study. Since we only provided NP led services, these findings have to be considered as possibly a halo effect for the users who previously did not have effective access to primary care.

The findings further extend assessment of satisfaction from NP care of previous comparison studies with physician care. An alternate explanation might be related to professional socialization processes in which NPs focus on a biopsychosocial perspective [18]. This perspective may account for the higher ratings for: NP information delivery; broader understanding of residents varied responsibilities at home, work, and schools; helping them to identify what to do and to cope with their concerns.

\section{Limitations}

This study focused on convenience samples of users and nonusers of NP led clinic services within two communities. The fixed 
questionnaire for interviews has had limited use within only this one city and population. The absence of information related to how many residents were approached, who refused to participate, how many choose to have the questionnaire read to them is not known leading to further study limitations. Hence, the absence of randomization and a comparison control community is a limitation. As such, the findings should be interpreted with caution. A further caution relates to the use of the same data set in testing the instrument psychometric analysis and using the same data in the study analyses.

The study was conducted within an urban medium-sized city and may not be applicable to rural areas or larger, more populated cities. The study was also conducted within a country with both government social service funding, and universal health care system access and may not be applicable in other settings where non-government funded health care is provided, or where primary care is not the access point for health care by the population.

\section{Implications of findings}

Further group comparison research is needed to study the impact of primary care services within other comparable services where NPs are situated in primary health care clinics with Family Physicians, perhaps with patients being randomly allocated to different conditions. Qualitative studies are also needed to further determine factors that influence residents' capacity in gaining access in managing their own health. Further studies using interventional approaches that focus on both the social environment of primary care clinics within collaborative partnership models of relationships are also needed.

Training programs for nurse practitioners and primary care health providers could be designed and evaluated that pay attention to building, implementing, and sustaining collaborative partnerships with clients. The findings from this study can be used as a basis for such programme designs.

\section{Conclusion}

This study focused on the ability of residents living within subsidized housing units within a southwestern Ontario city, to assess how gaining access to health care provided by NPs impact their own perceived health based on their capacity and competence following NP led services being created and provided within their community and their satisfaction with this access to care. A total of 110 residents who used the clinics services and 70 residents who chose to use their own health services participated in individual structured interviews. Data on residents were analyzed comparing users and non-users of the NP provided care on their: capacity and competence from their satisfaction with NP care led to their perceived health. The findings demonstrated a statistically significant relationship with residents' perceived Health with NP primary care was found, as compared to those residents who did not use these NP services. However, there are a number of limitations in this study that require the findings to be considered with caution.

\section{Acknowledgements}

Our sincere thanks are extended to Dr. Evelyn Vingilis, $\mathrm{PhD}$ for her in depth assistance with the statistical methodology input for this paper. We further wish to thank the nurse practitioners and residents who so willingly participated in this study. To the Ministry of Health \& LongTerm Care of Ontario, Canada who created and funded the creation of 25 nurse practitioner-led clinics within Ontario to demonstrate the value of Nurse Practitioners as independent practitioners providing primary health care to those in need. This study is about the evaluation of one of these sites in its early development.

\section{Funding}

Funding for this study was from the Government of Ontario, Canada's HealthForceOntario granting program.

\section{References}

1. World Health Organization (2008) Primary health care: Now more than ever. World Health Report 2008, Geneva

2. Davis K, Schoenbaum SC, Audet A-M (2005) A 2020 vision of patient-centered primary care. J Gen Intern Med 20: 953-957. [Crossref]

3. Gulliford M, Figueroa-Munoz J, Myfanwy M, Hughes D, Gibson B, et al. (2002) What does 'access to health care' mean? J Health Serv Res Policy 7: 186-188. [Crossref]

4. Orchard C (2011) Learning Labs Study Final Report. Submission to HealthForceOntario, Government of Ontario, Canada.

5. Mikkonen J, Raphael D (2010) Social determinants of health: The Canadian facts Toronto: York University School of Health Policy and Management. http://www. theecanadianfacts.org?

6. Lognon C, Hudon C, Goulet E, Boyer S, De Laat M, et al. (2015) Perceived barriers to healthcare for persons living in poverty in Quebec, Canada: the EQUIhelthThY project. Int J Equity Health 14: 3-11. [Crossref]

7. Wong S, Regan S (2009) Patient perspectives on primary health care in rural communities: Effects of geography on access, continuity and efficiency. Rural Remote Health 9: 1142. [Crossref]

8. Kuzel AJ, Woolf SH, Gilchrist VJ, Engel JD, LaVeist TA, et al. (2004) Patient reports of preventable problems and harms in primary health care. Ann Fam Med 2: 333-340. [Crossref]

9. Bandura A (2012) On the functional properties of perceived self-efficacy revisited. Journal of Management 38: 9-44.

10. Street Jr. RL, Epstein RM (2008) Key interpersonal functions and health outcomes: Lessons from theory and research on clinician-patient communication. In: Glanz K, Rimer BK, Viswanath K (Eds.). Health behavior and health education, theory, research, and practice ( $4^{\text {th }}$ ed). San Francisco, CA: Jossey-Bass. 237-269.

11. Auerbach SM (2000) Should patients have control over their own health care? Empirical evidence and research issues. Ann Behav Med 22: 246-259. [Crossref]

12. Ross CE, Mirowsky J (2000) Age and the gender gap in the sense of personal control. Soc Psychol Quart 65: 125-145.

13. Litaker D, Mion LC, Planavsky L, Kppes C, Mehta N, et al. (2003) Physician/nurse practitioner teams in chronic disease management: the impact on costs. Clinical effectiveness, and patients' perception of care. J Interprof Care 17: 223-237. [Crossref]

14. Lenz ER, Mundinger MO, Kane RL, Hopkins SC, Lin SX (2004) Primary care outcomes in patients treated by nurse practitioners or physicians: two-year follow-up. Med Care Res Rev 61: 323-351. [Crossref]

15. Mundinger MO, Kane RL, Lenz ER, Totten AM, Tsai W-Y, et al. (2000) Primary care outcomes in patients treated by nurse practitioners or physicians: A randomized trial. JAMA 283: 59-68. [Crossref]

16. Venning P, Durie M, Roland M, Roberts C, Leese B (2000) Randomized controlled trial comparing cost effectiveness of general practitioners and nurse practitioners in primary care. BMJ 320: 1048-1053.

17. Horrocks S, Anderson E, Salisbury C (2002) Systematic review of whether nurse practitioners working in primary health care can provide equivalent care to doctors. BMJ 324: 819-823.

18. Naidu A (2009) Factors affecting patient satisfaction and healthcare quality. Int $J$ Health Care Qual Assur 22: 336-381. [Crossref]

19. Agosta L (2009) Patient satisfaction with nurse practitioner-delivered primary healthcare services. J Am Acad Nurse Pract 21: 610-617. [Crossref]

20. Lafond AK, Brown L, Macintyre K (2002) Mapping capacity in the health sector: a conceptual framework. Int J Health Plann Manage 17: 3-22. [Crossref]

21. Griffith DM, Allen JO, DeLoney EH, Robinson K, Lewis EY, et al. (2010) Communitybased organizational capacity building as a strategy to reduce racial and health disparities. J Prim Prev 31: 31-39. [Crossref] 
22. Schoen C, Osborn R, How SH, Doty MM, Peugh J (2008) In chronic condition: Experiences of patients with complex health care needs, in eight countries. Health Aff 28: w1-w16. [Crossref]

23. Allen FM, Warner M (2002) A development model of health and nursing. J Fam Nurs 8: 96-135.

24. Ford-Gilboe M (2002) Developing knowledge about family health promotion by testing the developmental model of health and nursing. J Fam Nurs 8: 140-156.

25. SPSS Inc. Chicago, IL.

26. Tabachnick BG, Fidell LS (2014) Using multivariate statistics, 6th Ed. Harlow, Essex, UK: Pearson Education Ltd.
27. Pedhazur EJ (1997) Multiple regression in behavioral research (3 ${ }^{\text {rd }}$ Ed.). Orlando, FA, USA: Harcourt Inc.

28. Smith N, Baugh L, Thompson L, Thompson D (2001) Shaking out the cobwebs insights into community capacity and its relation to health outcomes. Community Development Journal 36: 30-41.

29. Campbell JL, Green J, Ramsay J (2001) Age, gender, socioeconomic, and ethnic differences in patients' assessments of primary health care. Qual Health Care 10: 9095. [Crossref]

30. Freudenberg N, Eng E, Flay B, Parcel G, Roger, T, et al. (1994) Strengthening individual and community capacity to prevent disease and promote health: In search of relevant theories and principles. Health Educ Q 22: 290-306. [Crossref]

Copyright: $₫ 2018$ Orchard CA. This is an open-access article distributed under the terms of the Creative Commons Attribution License, which permits unrestricted use, distribution, and reproduction in any medium, provided the original author and source are credited. 